\title{
Remnant gallbladder stones: a rare cause of post-cholecystectomy syndrome
}

Durmuş Ali Çetin, Ulaş Aday, Hüseyin Çiyiltepe, Ebubekir Gündeş, Emre Bozdağ, Orhan Uzun

Gastroenterological Surgery Department, Kartal Koşuyolu High Speciality and Training Hospital, Istanbul, Turkey

Submitted: 23 January 2017

Accepted: 7 February 2017

Arch Med Sci Civil Dis 2017; 2: e27-e28

DOI: https://doi.org/10.5114/amscd.2017.66385

Copyright $\odot 2017$ Termedia \& Banach

Laparoscopic cholecystectomy is a widely accepted surgical treatment for symptomatic gallstones. Symptoms disappear after surgery in approximately $85 \%$ of patients. Post-cholecystectomy syndrome is defined as the continuation of pre-existing clinical symptoms or the development of new symptoms after cholecystectomy. These patients most often present with upper abdominal pain (mostly right upper quadrant pain) and dyspepsia complaints. Symptoms may occur in early and late post-operative periods ( $2^{\text {nd }}$ postoperative day -25 years) [1]. The causes of post-cholecystectomy syndrome may be biliary or extrabiliary. Remnant gallbladder is a very rare cause of post-cholecystectomy syndrome [2]. We present a case of symptomatic remnant gallbladder which is a rare cause of post-cholecystectomy syndrome.

A 67-year-old male patient presented with occasional recurrent right upper quadrant pain and dyspeptic complaints. The patient had laparoscopic cholecystectomy due to acute cholecystitis about 10 months ago and endoscopic retrograde cholangiopancreatography (ERCP) due to choledocholithiasis about 3 months after the operation. On the physical examination, trocar site incisions were observed and there was slight tenderness in the right upper quadrant. Laboratory values were normal. In the upper gastrointestinal system endoscopy there were no features other than antral gastritis.

Abdominal ultrasonography (USG) revealed a posterior shadow consistent with calculus in the gallbladder lodge. Unenhanced computed tomography (CT) of the upper abdomen and magnetic resonance cholangiopancreatography (MRCP) revealed a small line-shaped area in the gallbladder lodge consistent with a $15 \mathrm{~mm}$ sized stone at the level of the neck region connected to the cystic duct. The diameter of the choledochus was approximately 7-8 $\mathrm{mm}$ and no stone was seen (Figures 1 and 2). The cystic duct and remnant gallbladder were observed in the patient operated with preoperative diagnosis of remnant gallbladder stones and remnant cystic duct stones. Cholecystectomy was performed for the patient, who had an approximately $1.5 \mathrm{~cm}$ stone in the bladder neck. On the $4^{\text {th }}$ postoperative day, the patient was discharged without any problems.

Post-cholecystectomy syndrome is defined as the continuation or recurrence of symptoms after cholecystectomy. Remnant gallbladder, which is one of the rare causes of post-cholecystectomy syndrome, can be seen due to inadequate cholecystectomy, partial cholecystectomy or congenital gallbladder duplication. The most important cause of remnant gallbladder is the remaining gallbladder tissue in the partial cholecys-

\author{
Corresponding author: \\ Durmuş Ali Çetin \\ Gastroenterological Surgery \\ Department \\ Kartal Koşuyolu \\ High Speciality and \\ Training Hospital \\ 34650 Istanbul, Turkey \\ Phone: +905054378667 \\ E-mail: drdurmusalicetin@ \\ gmail.com
}




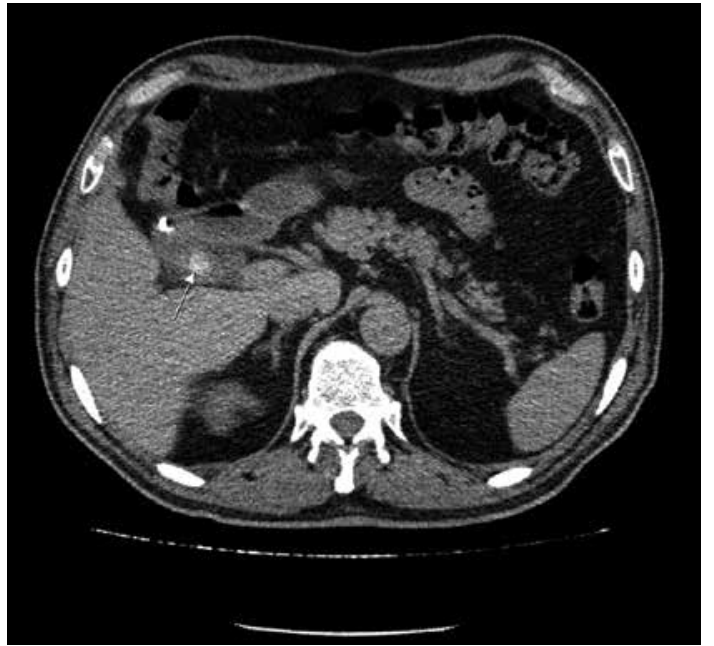

Figure 1. Abdominal CT axial plan - remnant gallbladder stone

tectomy surgery due to poor visualization of the anatomy of the cystic duct and gallbladder junction for reasons such as hemorrhage, adhesion, or inflammation. Partial cholecystectomy is more common in cholecystectomy which is performed after acute cholecystitis [3, 4].

This can lead to remaining stones in the remnant section or the stone can form over time due to a long remnant cystic duct or gallbladder neck stump. Symptoms may occur in early and late postoperative periods. The most important symptoms of post-cholecystectomy syndrome are abdominal pain, nausea/vomiting, dyspeptic complaints, jaundice and fever [1, 3]. Our case presented with right upper quadrant pain and dyspepsia complaints. There was a history of laparoscopic cholecystectomy due to acute cholecystitis. Biliary and extra-biliary causes are present in the differential diagnosis of post-cholecystectomy syndrome. Biliary causes are: stone in the cystic duct stump, choledocholithiasis, biliary stricture, biliary leakage, remnant cystic duct or gallbladder, gallbladder duplication, biliary dyskinesia and sphincter of Oddi dysfunction. Extra-biliary causes are: reflux esophagitis, peptic ulcer, irritable bowel syndrome and pancreatic pathologies [1, 2, 5].

The radiological approach in post-cholecystectomy syndrome is cholangiography as the gold standard following USG or CT. The MRCP is an alternative to invasive cholangiography techniques in evaluation of the biliary system and has a very important place as a primary imaging modality [6]. It allows imaging of the cystic ducts and bile ducts as well as evaluation of the gallbladder. The ERCP is a preferred method allowing diagnosis and treatment after initial evaluation of post-cholecystectomy syndrome [5]. In our case, differential diagnosis was made using USG, CT and MRCP. Complementary cholecystectomy provides a definitive

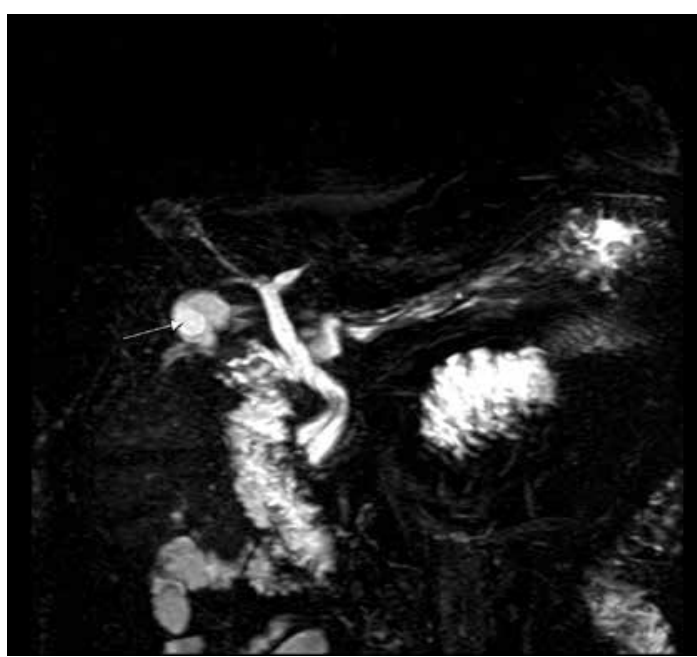

Figure 2. Abdominal MRI coronal plan - remnant gallbladder

treatment for the gallbladder remnant and can be performed laparoscopically [7]. The operation was initiated laparoscopically, but open surgery was performed due to inability to adequately reveal the anatomy and the risk of major biliary injury.

In conclusion, remnant gallbladder stones should be kept in mind in differential diagnosis in patients presenting with post-cholecystectomy syndrome after cholecystectomy in case of detection of stone and sac-like tissue on the gallbladder lodge in clinical and radiological examinations.

\section{Conflict of interest}

The authors declare no conflict of interest.

\section{References}

1. Jaunoo SS, Mohandas S, Almond LM. Postcholecystectomy syndrome (PCS). Int J Surg 2010; 8: 15-7.

2. Schofer JM. Biliary causes of postcholecystectomy syndrome. J Emerg Med 2010; 39: 406-10.

3. Lum YW, House MG, Hayanga AJ, Schweitzer M. Postcholecystectomy syndrome in the laparoscopic era. J Laparoendosc Adv Surg Tech A 2006; 16: 482-5.

4. Jayant M, Kaushik R. Presentation and management of gallbladder remnant after partial cholecystectomy. Trop Gastroenterol 2013; 34: 99-103.

5. Karayalçın K. Postcholecystectomy syndrome. Turkiye Klinikleri J Int Med Sci 2006; 2: 38-40.

6. Girometti R, Brondani G, Cereser L et al. Post-cholecystectomy syndrome: spectrum of biliary findings at magnetic resonance cholangiopancreatography. $\mathrm{Br} J$ Radiol 2010; 83: 351-61.

7. Parmar AK, Khandelwal RG, Mathew MJ, Reddy PK. Laparoscopic completion cholecystectomy: a retrospective study of 40 cases. Asian J Endosc Surg 2013; 6: 96-9. 